Bor, S., Feiwal, M. \& Chanarin, I (1969) Vitiligo and its aetiological relationship to organ-specific auto-immune disease. British Journal of Dermatology, 81, 83.

Brostoff, J., Bor, S. \& Feiwal, M. (1969) Auto-antibodies in patients with vitiligo. Lancet, ii, 177.

Cunliffe, W.J., Hall, R., Newall, D.J. \& Stevenson, G.J. (1968) Vitiligo, thyroid disease and auto-immunity. British Journal of Dermatology, 80, 135.
DAWBER, R.P.R. (1968) Vitiligo in mature-onset diabetes mellitus. British Journal of Dermatology, 80, 275.

DAWBER, R.P.R. (1970) Late onset vitiligo associated with auto-immune disease. Postgraduate Medical Journal, 46, 276.

Karlish, A.J. \& MaCGregor, G.A. (1970) Sarcoidosis, thyroiditis and Addison's disease. Lancet, ii, 330.

Kopf, A.W. (1969) Discussion on multiple halo naevi. Archives of Dermatology, 99, 187.

Postgraduate Medical Journal (February 1972) 48, 117-118.

\title{
Haemangioma of the bladder
}

\author{
A. Morales* \\ M.D. \\ Department of Urology, Queen's University, Kingston, Ontario
}

VASCULAR tumours of the bladder are rare. Less than fifty cases have been reported in the literature at the time of writing, and few of these have been documented histologically (Fuleihan \& Cordonnier, 1969). In this paper a case of cavernous haemangioma of the bladder is presented together with the histological features and results of surgical treatment.

\section{Case report}

A 15-year-old boy was referred to hospital with a history of intermittent attacks of gross haematuria since the age of 2 years. The haematuria appeared to be related to physical exertion and, as he grew older, he was able to state that each episode was associated with diffuse back pain. He had been treated successfully in the past by bed rest alone, the haematuria usually stopping within a few days. However, in view of the persisting nature of his symptoms, he was admitted to hospital for further investigation. He admitted no other urological symptoms and his general health was good.

On examination, he was a well-developed Caucasian boy, slightly pale and in no distress. BP $120 / 70 \mathrm{mmHg}$ and the pulse $78 / \mathrm{min}$. The haemoglobin was $10 \cdot 2 \mathrm{~g} / 100 \mathrm{ml}$ with a haematocrit of $34 \%$. The urine contained albumin and, on microscopy, two or three red blood cells were seen per high power field. Coagulation studies were normal. The only abnormality seen on the excretory urogram was a filling defect on the right lateral wall of the bladder (Fig. 1). At cystoscopy, a large $(2 \times 3 \mathrm{~cm})$ bluish-red sessile mass was noted in the right postero-lateral wall of the bladder. There were four similar tumours of less than $0.5 \mathrm{~cm}$ in diameter located at the dome. A biopsy of the larger mass was taken and was reported to be 'cystitis with numerous blood vessels'. Three days after cystoscopy, an exploration of the

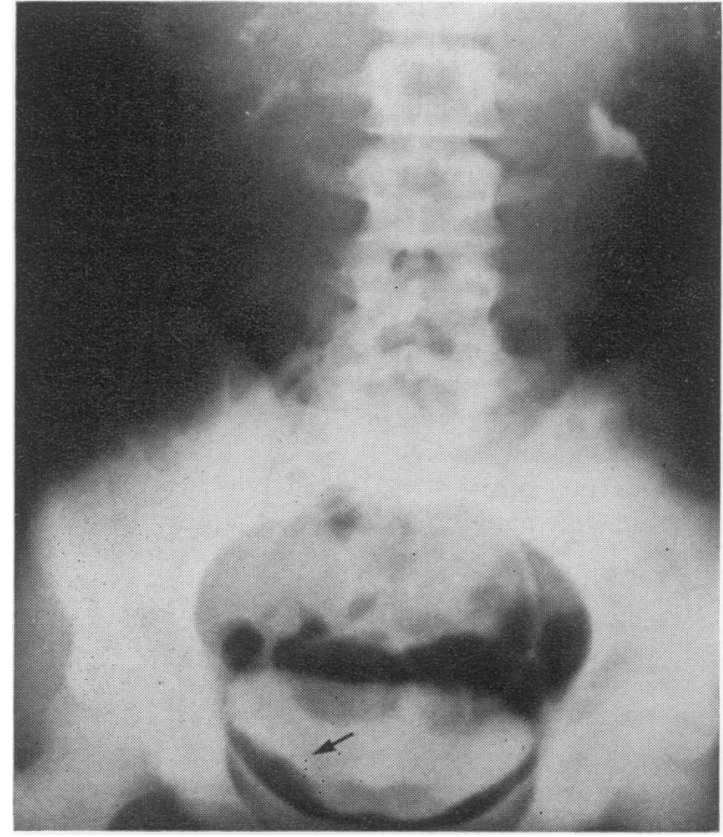

Fig. 1. Intravenous pyelogram. Arrow shows a filling defect on the right lateral wall of the bladder.

bladder was carried out because of severe, persisting haematuria which was found to be originating from the biopsy site. The large tumour was removed by segmental cystectomy and the smaller lesions were fulgurated. The patient made an uneventful recovery, and on removal of the urethral catheter, the urine

* Present address: Department of Urology, Royal Infirmary, Aberdeen. 
was clear. Three years later, there has been no recurrence of haematuria, and an intravenous pyelogram is normal. Histological examination of the excised tumour showed the characteristic features of a cavernous haemangioma.

\section{Discussion}

Vesical tumours are rare in young people, and those of vascular origin are unusual in any age group. The cavernous haemangiomata are congenital tumours. They often increase in size due to growth of the original vessels and also to the formation of new vessels which spread to contiguous tissues (Campbell, 1964; Herbut, 1959). Fuleihan \& Cordonnier (1969) pointed out that $65 \%$ of these tumours occur in patients less than 15 years old. They are more common among Caucasians (Herbut, 1959). The presenting symptom is usually painless haematuria. The bleeding may te copious, and has even been fatal (Williams \& Schistad, 1964). Approximately $20 \%$ have associated haemangiomata of the skin (Stanley, 1966).

Diagnosis can be difficult since the cystogram may reveal only a non-specific filling defect. Usually the diagnosis is made at cystoscopy when the tumour is seen with its characteristic bluish-red colour. The lesion must be distinguished from other pigmented conditions such as endometriosis and melanoma. When haemangioma is suspected at endoscopy, a biopsy may be hazardous. The patient should be kept under close observation if this is carried out, and it should be realized that immediate open surgery may be required.

Numerous surgical methods have been employed to treat haemangioma of the bladder, including cystoscopic fulguration (Hamsher, Farrar, \& Moore, 1958), transurethral resection (Kahle, Maltry \& Vickery, 1942), partial cystectomy (De la Pena, 1949), and subtotal cystectomy (Fuleihan \& Cordonnier, 1969). Recurrences may occur when removal has been incomplete or the tumour shows malignant degeneration, otherwise surgical results are excellent. Because the great majority of these lesions are benign, Liang (1958) believes that surgical treatment is too radical, and has described two cases treated with radiotherapy with satisfactory results. He maintains that $2500 \mathrm{r}$, given in divided doses to avoid cystitis, will be effective in the majority of cases, and that more drastic surgical procedures should be reserved for the radio-resistant lesions.

\section{References}

Campbell, F.M. (1964) Urology, 2nd edn. W. B. Saunders, Philadelphia.

De la Pena, A. (1949) Simple hemangioma of the bladder. Journal of Urology, 55, 696.

Fuleihan, F.M. \& CoRdonNiER, J.J. (1969) Hemangioma of the bladder; report of a case and review of the literature. Journal of Urology, 102, 581.

HAMSher, J.B., FARRAR, T. \& MoORE, T.D. (1958) Congenital malformations and vascular tumors involving the urinary tract; diagnosis and surgical treatment. Journal of Urologyo 80, 299.

Herbut, P.A. (1959) Pathology, 2nd edn. Lea \& Lebinger Philadelphia.

Kahle, P.J., Maltry, E. \& Vickery, G. (1942) Hemangiom夈 of the bladder; report of an additional case. Journal of Urology, 47, 267.

LiANG, D.S. (1958) Hemangioma of the bladder. Journal of Urology, 79, 956.

STANLEY, K.E. (1966) Hemangioma-lymphangioma in a child. Report of a case with associated tumors of the external genitalia. Journal of Urology, 96, 51.

Williams, D.I. \& Schistad, G. (1964) Lower urinary tract tumors in children. British Journal of Urology, 36, 51. 